\title{
Comparative analysis of titanium coating on cobalt-chrome alloy in vitro and in vivo direct metal fabrication vs. plasma spraying
}

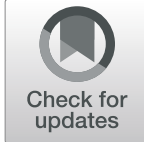

\author{
Dongwhan Suh ${ }^{1,2}$, Woo Lam Jo ${ }^{1,3}$, Seung Chan Kim ${ }^{1,4}$, Yong Sik Kim ${ }^{1,3}$, Soon Yong Kwon ${ }^{1,4}$ and \\ Young Wook Lim ${ }^{1,3^{*}}$ (D)
}

\begin{abstract}
s
Background: Titanium surface coating on cobalt-chromium ( $\mathrm{CoCr}$ ) alloy has characteristics desirable for an orthopedic implant as follows: strength, osteointegrative capability, and biocompatibility. Creating such a coated surface takes a challenging process and two dissimilar metals are not easily welded. In our study, we utilized additive manufacturing with a 3D printing called direct metal fabrication (DMF) and compared it to the plasma spraying method (TPS), to coat titanium onto CoCr alloy. We hypothesized that this would yield a coated surface quality as acceptable or better than the already established method of plasma spraying. For this, we compared characteristics of titanium-coated surfaces created by direct metal fabrication method (DMF) and titanium plasma spraying (TPS), both in vitro and in vivo, for (1) cell morphology, (2) confocal microscopy images of immunofluorescent assay of RUNX2 and fibronectin, (3) quantification of cell proliferation rate, (4) push-out biomechanical test, and (5) bone histomorphometry.
\end{abstract}

Method: For in vitro study, human osteoblast cells were seeded onto the coated surfaces. Cellular morphology was observed with a scanning electron microscope. Cellular proliferation was validated with ELISA, immunofluorescent assay. For in vivo study, coated rods were inserted into the distal femur of the rabbit and then harvested. The rods were biomechanically tested with a push-out test and observed for histomorphometry to evaluate the microscopic bone to implant ratio.

Result: For cell morphology observation, lamellipodia and filopodia, a cytoplasmic projection extending into porous structure, formed on both surfaces created by DMF and TPS. The proliferation of the osteoblasts, the DMF group showed a better result at different optic density levels $(p=0.035,0.005,0.001)$. Expression and distribution of fibronectin and Runx-2 genes showed similar degrees of expressions. The biomechanical push-out test yielded a similar result ( $p=0.714)$. Histomorphometry analysis also showed a similar result $(p=0.657)$.

Conclusion: In conclusion, DMF is a method which can reliably create a proper titanium surface on CoCr alloy. The resulting product of the surface shows a similar quality to that of the plasma spraying method, both in vivo and in vitro, in terms of biological and mechanical property.

Keywords: Titanium surface coating, Direct metal fabrication, Osteointegration, 3D printing

\footnotetext{
* Correspondence: cmcoslpart2@gmail.com

'Department of Orthopaedic Surgery, College of Medicine, The Catholic University of Korea, Seoul, Republic of Korea

${ }^{3}$ Department of Orthopaedic Surgery, Seoul St. Mary's Hospital, College of Medicine, The Catholic University of Korea, Seoul, Republic of Korea

Full list of author information is available at the end of the article
}

C C The Author(s). 2020 Open Access This article is licensed under a Creative Commons Attribution 4.0 International License, which permits use, sharing, adaptation, distribution and reproduction in any medium or format, as long as you give appropriate credit to the original author(s) and the source, provide a link to the Creative Commons licence, and indicate if changes were made. The images or other third party material in this article are included in the article's Creative Commons licence, unless indicated otherwise in a credit line to the material. If material is not included in the article's Creative Commons licence and your intended use is not permitted by statutory regulation or exceeds the permitted use, you will need to obtain permission directly from the copyright holder. To view a copy of this licence, visit http://creativecommons.org/licenses/by/4.0/. The Creative Commons Public Domain Dedication waiver (http://creativecommons.org/publicdomain/zero/1.0/) applies to the data made available in this article, unless otherwise stated in a credit line to the data. 


\section{Introduction}

Strength, osteointegrative capability, and biocompatibility are the qualities desirable for an orthopedic implant [1]. Until now, endeavor to meet the optimal surface condition for implants to incorporate such characteristics is ongoing [2]. While it has been known that titanium surface coating on cobalt-chromium $(\mathrm{CoCr})$ alloy would yield such quality [3-5], this process had remained challenging [6]. To create or combine metal on the metal surface, casting or forging plus additive manufacturing processes are required. The additive manufacturing process is known to be dependent on types of metals, and titanium itself poses a challenge to the process due to its high melting point and chemical composition [7-9]. The configuration of the end-product, whether there be a groove or an angle is a significant variable to the process [8]. Thus, it had been considered as a challenge to create cobalt-chromium and titanium alloy with conventional techniques [4].

Plasma spraying is an established, commercially available method used in the additive manufacturing (AM) process. It has been known for its versatility in application and availability $[10,11]$. However, this method could cause (1) structural deformation, (2) delamination of the coated surface, (3) non-optimal porosity, (4) decrement in fatigue strength, and (5) relatively high-cost and complexity of the process [8]. Direct metal fabrication (DMF) technique, on the other hand, is thought to be able to overcome the aforementioned shortcomings of the plasma spraying method by minimally affecting the surrounding materials; without creating a wide surface of thermal alteration and extensive weld line $[6,12-$ 14]. Also, DMF does not require vacuum conditions or other types of conditioning prior to application. Thus, the range of applicability could be wider with this method [12].

DMF is a novel, additive manufacturing (AM) method that utilizes 3D printing technology [15]. With a fully automated process, the surface quality and characteristics can be controlled to customize the desired configuration, pore size, and surface roughness [16]. The method allows a stable coating-substrate interface between different physical and chemical properties [17]. We hypothesized that DMF could produce titanium-coated surface as good or better than the already established plasma spraying method. To test our hypothesis, we compared titanium coating with DMF and titanium plasma spraying (TPS) on $\mathrm{CoCr}$ alloy surface both in vitro and in vivo for (1) cell morphology, (2) confocal microscopy images of immunofluorescent assay of RUNX2 and fibronectin, (3) quantification of cell proliferation rate through ELISA, (4) interfacial shear strength (push-out biomechanical test), and (5) bone histomorphometry.

\section{Method}

We compared DMF and titanium plasma spray (TPS) coatings of $\mathrm{CoCr}$ alloy surface both in vitro and in vivo, to find if there is a difference in terms of cell morphology, biocompatibility, cell proliferation rate, shear strength, and histomorphometry. For in vitro study, with AM technology-based DMF method, Pure Ti (CPTi powder grade 2, ASTM F1580) powders between the size of 45-150 um were melted and laminated using a selective laser on $\mathrm{CoCr}$ alloy surface. A computerassisted design (CAD) program was used prior to executing the actual coating process to design porous structure to simulate the porous properties of cancellous bone (NX-based coating CAM for Insstek, Siemens). The laser-irradiated surface of $\mathrm{CoCr}$ alloy formed a melted pool, by following the path of a pre-programmed grid-shaped tool with $80 \mathrm{~W}$ laser power, $1.5 \mathrm{~m} / \mathrm{min}$ scan speed, and $2.2 \mathrm{~g} / \mathrm{min}$ power delivery rate. Next, metal powders were sprayed and laminated onto the melted surface, which is different from selective laser melting (SLM) and electron beam melting (EBM) [15]. To give the porous surface an irregularity of thickness and shape, the coating layer was twice coated; once with a thickness of $300 \mathrm{um}$ and then with a thickness of $500 \mathrm{um}$. In the plasma spraying method which we utilized to compare to DMF, Ti powder for coating was injected into plasma gas stream which is heated up to $20,000^{\circ} \mathrm{C}$. With high kinetic force, the powder was shot onto the substrate and then melted, forming a porous structure. Scanning electron microscopy was used to assess the structure and morphology of the produced surfaces [11].

Osteoblasts derived from human mesenchymal cells were prepared [18]. $5 \times 10^{4}$ osteoblasts were seeded onto DMF- and TPS CoCr-coating specimens. After $6 \mathrm{~h}$ of seeding of cells in each implant, the media was removed and then the cells were washed with PBS 3 times. After adding $2 \%$ glutaraldehyde-PBS solution, these cells were stabilized for $2 \mathrm{~h}$. The cells were then washed with dextrose water solution 3 times. At 30-min intervals, the cells were dehydrated with $50-100 \%$ ethanol solutions. The ethanol was removed, and the cells were left at room temperature to allow for complete ethanol evaporation. Two surfaces were then characterized by scanning electron microscope (JEOL JSM-6700F; JEOL, Ltd, Tokyo, Japan) after the test specimens had been coated with platinum.

The seeded cells on the coated surfaces were incubated for 24, 48, 72, and $96 \mathrm{~h}$. The medium was replaced with a fresh medium before measuring cell proliferation using the Cell Titer 96 Nonradioactive Cell Proliferation Assay (Promega Corp, Madison, WI), according to the manufacturer's instructions. Cell proliferation assay is a colorimetric method for determining the number of viable cells. In this study, the number of viable cells was measured at $490 \mathrm{~nm}$ using an enzyme-linked immunosorbent assay (ELISA) reader (Bio-Tek Instruments, Inc., Winooski, VT) [19]. 
The differentiation of osteoblast cells was evaluated by immunofluorescence staining for the Runx-2 and fibronectin genes $[5,20]$. After 21 days of incubation, irrigation with PBS three times, and stabilization with $4 \%$ paraformaldehyde for $10 \mathrm{~min}$, the cells were incubated to use primary antibodies to RUNX-2 and fibronectin (1: 100, Abcam, Cambridge, England) overnight at $4{ }^{\circ} \mathrm{C}$. After incubation with primary antibodies, cells were incubated with secondary Alexa Fluor 594 goat anti-rabbit and mouse (Invitrogen, CA, USA) for $1 \mathrm{~h}$ at room temperature. The cells were mounted with DAPI mount for $10 \mathrm{~min}$, and the cells were washed with PBS. We confirmed the differentiation of osteoblast cells with colocalization by expression of DAPI, RUNX-2, and fibronectin under high-powered magnification via a confocal microscope (Olympus, Tokyo, Japan).

For in vivo study, 20 full-grown rabbits $(>3.2 \mathrm{~kg})$ were assigned as experimental subjects. All experimental procedures were approved by the Institutional Animal Care and Use Committee of the institution. DMF- and TPScoated rods were inserted surgically into intramedullary canals of each distal femur separately. Specimens were harvested 3 months after the surgery and push-out test, and histomorphometric analysis was conducted. Each harvested distal femur was sliced at the two ends of the rods, and foreign substances were removed. To test the shear strength of the bone-implant interface of the products, a jig of the universal testing machine (Daekyung tech DTU-900MH30kN, Korea) was positioned vertically along the long axis of the rod and then a push-out test was performed at a push rate of $1 \mathrm{~mm} / \mathrm{min}$ (Fig. 1). The push strength was recorded until the rod became dissociated with the femur or breakage of the femur occurred [3].

The harvested bone tissue was dehydrated with alcohol in stages and soaked in Technovit 7200 resin (Heraeus Kulzer, Germany). The soaked tissue was embedded in paraffin for curing via a light system (Exakt, Germany). The block was sliced into $200-\mu$ m-thick sections with a hard tissue slicer (Struers, Germany). These sections were then stained with hematoxylin and eosin (H\&E; Sigma-Aldrich). Microscopy images were obtained by $\times 12.5, \times 40$, and $\times 100$ (BX51, Olympus, Japan). The specimens from each implant were analyzed by determining the percentage of direct contact between the mineralized bone and the $\mathrm{CoCr}$ alloy surface from intersection counting, using an integrative eyepiece with parallel sampling lines at a magnification of $\times 100$ [21].

For statistical analysis, we compared the cell proliferation assays on the two surfaces, mean interfacial shear strength and bone-to-implant contact percentage of the two different surfaces using a Wilcoxon signed-rank test. Statistical analysis was performed using SPSS $^{\oplus} 18.0$ software (SPSS, Inc., Chicago, IL).

\section{Result}

In vitro

For cell morphology observation, both TPS- and DMFcoated surfaces were covered with osteoblast which means cell adhesion appeared extensive on both groups (Fig. 2). Lamellipodia and filopodia, a cytoplasmic projection extending into porous structure, formed on both surfaces.

Cell proliferation on both surfaces was evaluated with ELISA. The number of viable cells was measured at $490 \mathrm{~nm}$ (Fig. 3). As to the proliferation of the osteoblasts, the DMF group showed a better result; optical density of $0.15,0.32,0.44$, and 0.61 at $24,48,72$, and $96 \mathrm{~h}$ while the TPS groups showed $0.06,0.15,0.22$, and 0.28 . Differences were statistically significantly higher in the DMF group at 48, 72, and $96 \mathrm{~h}(p=0.035,0.005$, and 0.001 , respectively). For biocompatibility assay to validate the differentiation and proliferation of osteoblasts, immunofluorescent staining with antibodies to Runx-2 and fibronectin were conducted (Fig. 4). Expression and distribution of fibronectin and Runx-2 genes showed a similar degree of expression on both surfaces.

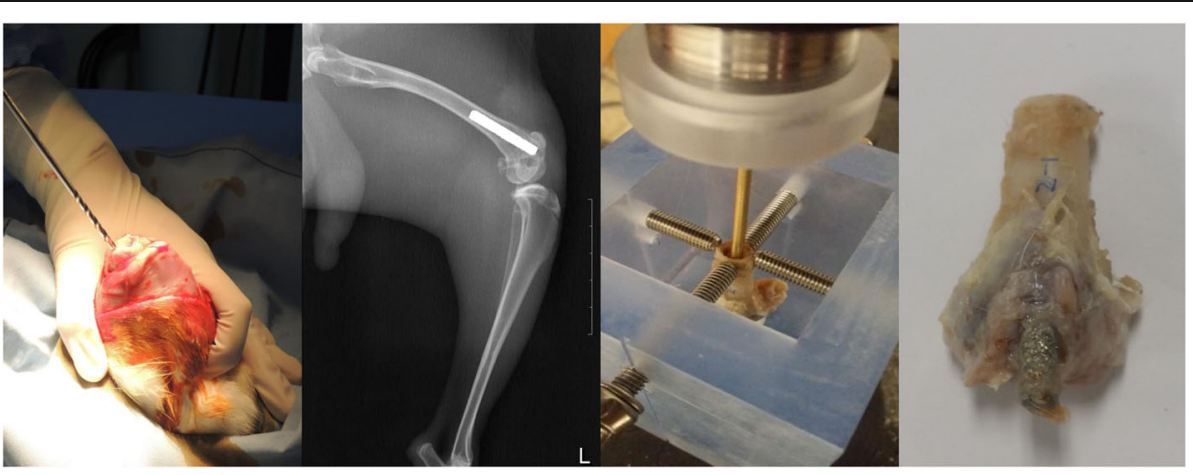

Fig. 1 DMF- and TPS-coated rods are inserted separately in the rabbit distal femur and then harvested 3 months after, for in vivo biomechanical analysis. Rods were connected to a jig for push-out test until the femur breaks or the rod comes out 


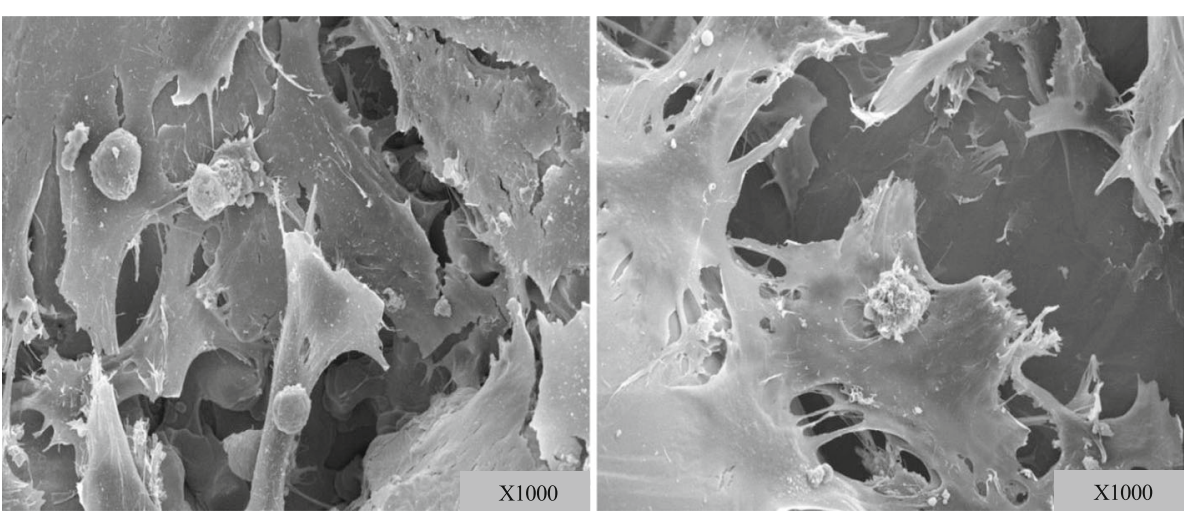

Fig. 2 Cell morphology. SEM images of the surfaces of the TPS (left) and DMF (right) coat $(\times 1000)$. Both surfaces showed similar characteristics. Osteoblast adhesion to surface with lamellipodia and filopodia was visible which means that the surfaces provided environment osteointegration

\section{In vivo}

The biomechanical push-out test resulted in $2.46 \mathrm{MPa}$ from the TPS rod and 2.53 MPa from the DMF rod ( $p=$ $0.714)$. Histomorphometric analysis showed that harvested rods from the rabbit yielded the bone to implant contact ratio of $56.4 \pm 6.7 \%$ and $57.3 \pm 7.2 \%$, from TPS and DMF, respectively ( $p=0.657)$ (Fig. 5).

\section{Discussion}

Our study investigated whether DMF could yield a comparable titanium-coated surface to that of TPS. We hypothesized that a novel $3 \mathrm{D}$ printing method utilizing additive manufacturing can provide the titanium-coated surface in terms of biocompatibility, osteointegration, and biomechanics both in vitro and in vivo, as competent as a product created by the established method of TPS. As for in vitro, the coated surfaces from both methods created a porous structure similar to that of the cancellous bone which could provide foothold for osteoblast [22]. Adhered osteoblasts displayed cellular projectiles such as lamellipodia and filopodia as we could observe from cell morphology on the scanning electron microscope. As to whether those osteoblasts were proliferating on the surfaces, ELISA was conducted for quantification and found that both surfaces allowed osteoblasts for proliferation. However, absorbance at $490 \mathrm{~nm}$ shows that the proliferation rate of

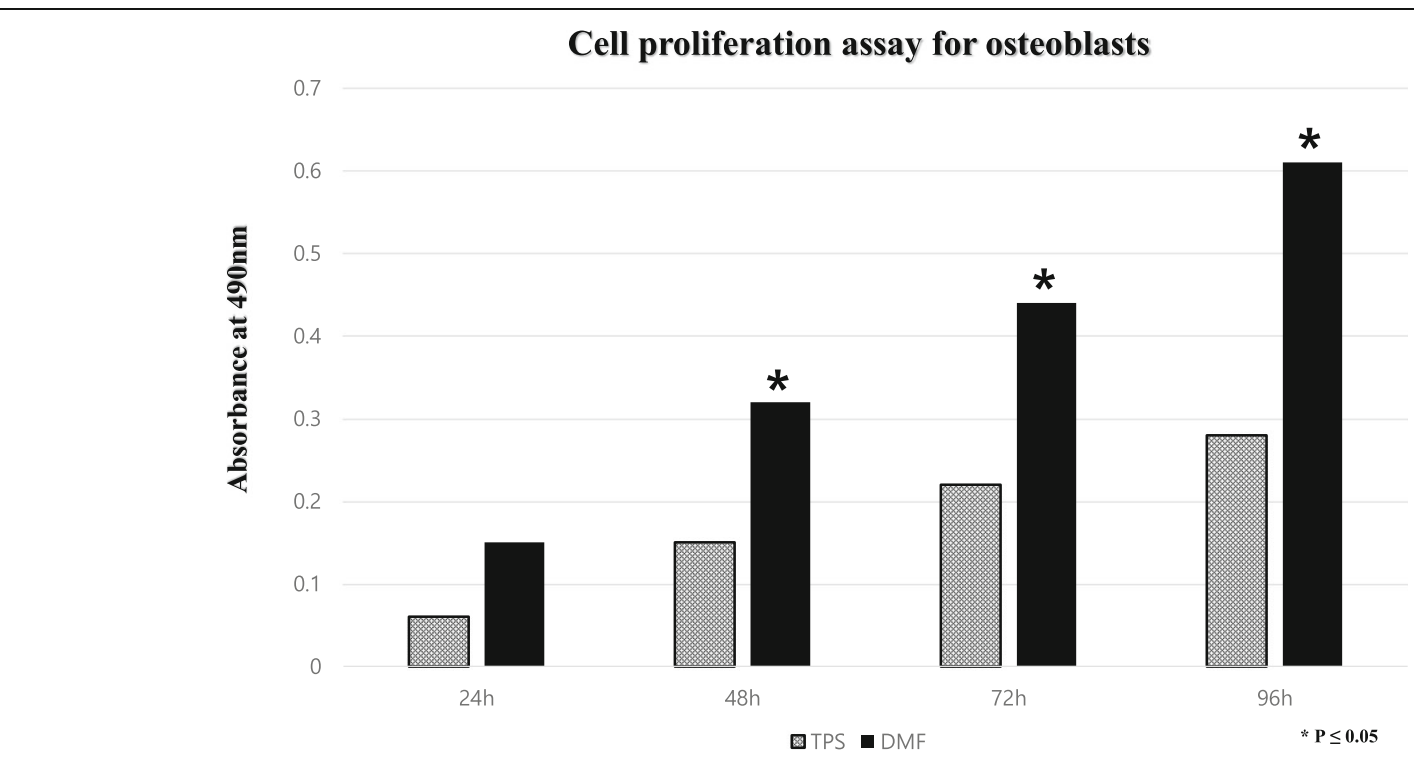

Fig. 3 Cell proliferation. ELISA of the surfaces of TPS and DMF coating. As to the proliferation rate of the osteoblasts, the DMF group showed a better result, superior to the plasma-sprayed group on $24,48,72$, and $96 \mathrm{~h}$ of incubation $(p<0.001)$ 

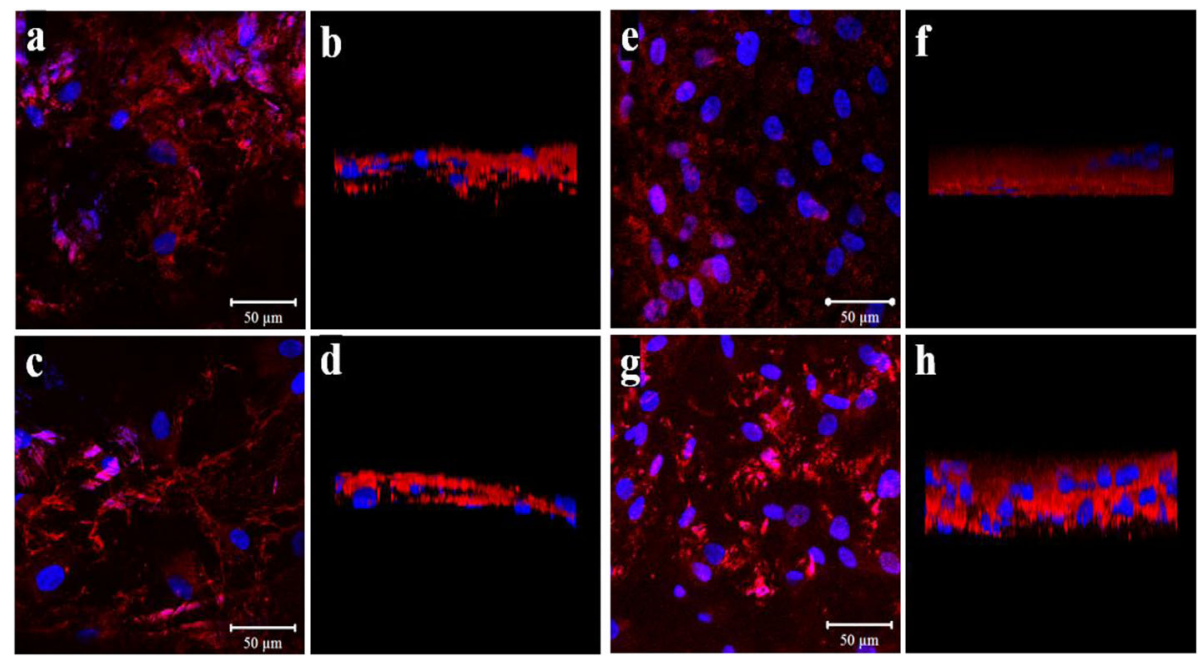

Fig. 4 Immunofluorescent staining of Runx-2 and fibronectin expression in osteoblasts. Stained with reds are Runx-2 and fibronectin. TPS-coated surface stained with fibronectin is showed in $\mathbf{a}$ and $\mathbf{b}$ while fibronectin staining of DMF surface is showed in $\mathbf{c}$ and $\mathbf{d}$. Runx-2 expression of TPS surfaces is showed in $\mathbf{e}$ and $\mathbf{f}$ while that of DMF surface are showed in $\mathbf{g}$ and $\mathbf{h}$. Blue stains are of DAPI, which were used as counterstain. Overall expression within the set area is shown in $\mathbf{a}, \mathbf{c}, \mathbf{e}$, and $\mathbf{g}$. The thickness of the stained layer is shown in $\mathbf{b}, \mathbf{d}, \mathbf{f}$, and $\mathbf{h}$

the osteoblasts on the DMF surface was higher, compared to the plasma-sprayed group on $24,48,72$, and $96 \mathrm{~h}$ after incubation $(p<0.001)$. Runx-2 and fibronectin expression are specific to osteoblast [20, 23]; thus, an immunofluorescent assay for Runx-2 and fibronectin was conducted for visualization and validation of osteoblast proliferation. Runx-2 and fibronectin were both expressed with a similar degree of the signal intensity in DMF- and TPS-coated surfaces. This shows that biocompatibility and osteointegrative quality were achieved in both surfaces. As for in vivo study, a push-out biomechanics study to test the shear strength of the implant and its histomorphometry was conducted. The push-out test resulted in $2.46 \mathrm{MPa}$ from TPS and 2.53 MPa from DMF ( $p=0.714)$. It reveals that there is no statistically significant difference between 2 rods in terms of shear strength. Histomorphometric analysis showed that harvested rods from the rabbit yielded the bone to implant contact ratio of $56.4 \pm 6.7 \%$ and $57.3 \pm 7.2 \%(p=0.657)$, which renders this result as statistically not significant. Our results of in vivo and in vitro study show that DMF- and TPS-coated surface were similar in biocompatibility, osteointegration, and

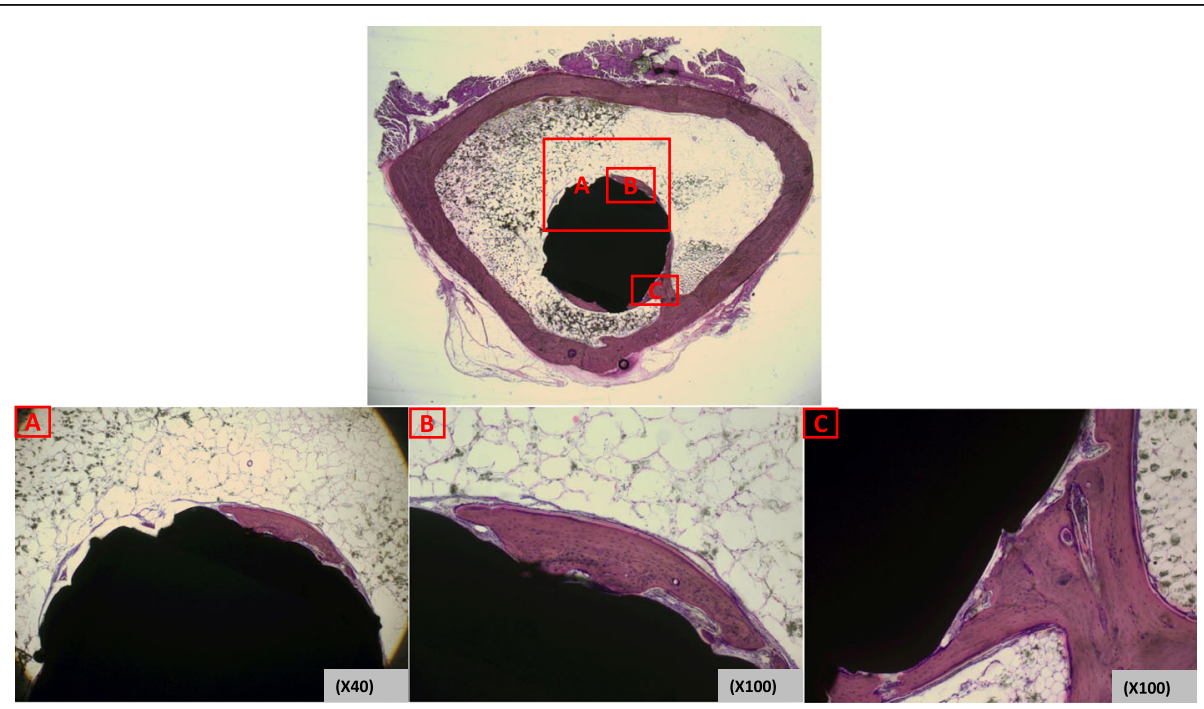

Fig. 5 Histomorphometry of bone-implant cross-section. Cross-sections of the bone to implant contact areas $\mathbf{a}$, $\mathbf{b}$, and $\mathbf{c}$ are observed. Cellular matrix component stained with hematoxylin is on the contact surface of the implant 
mechanical strength. While plasma spraying is already an established method for surface coating, it has some recognized shortcomings such as the requirement for a vacuum environment for processing and difficulty to adjust to various angulation and curvature of the surface of a welded plane. DMF has advantages over TPS that it does not require such manufacturing conditioning and can be more fine-tuned as to powder application, undercooling of welding metal and to curved surfaces. The fact that the whole process can be automated with 3D printing technology is also an advantage that it can be utilized for the personalization of implant design. This study has a few limitations. First, it was not conducted in a clinical setting and thus could not conclude the real applicability of the coating method. Second, our sample size for in vivo study was relatively small and was in the animal study. This renders a need for a further study focused on clinical application in a larger scale. Nonetheless, the result of our study shows that a novel, DMF method is applicable to implant surface coating and that it can be an alternative to the previously existing coating method.

\section{Conclusion}

In conclusion, DMF is a novel method which can be utilized in the creation of $\mathrm{Ti}-\mathrm{CoCr}$ alloy. The resulting product of the alloy shows a similar quality to that of TPS, both in vivo and in vitro, in terms of biological and mechanical properties. Moreover, DMF applied with 3D printing technology has an advantage over the conventional TPS method in creating alloy surfaces where the curved surface poses technical challenges due to the conformation. We believe this method could be used to create metal surfaces of orthopedic implants with osteointegrative and biocompatible quality.

\section{Abbreviations}

Ti: Titanium; CoCr: Cobalt-chromium; ASTM: American Society for Testing and Materials; CPTi: Commercially pure titanium; DMF: Direct metal fabrication; TPS: Titanium plasma spraying; ELISA: Enzyme-linked immunosorbent assay

\section{Acknowledgements}

Not applicable.

\section{Authors' contributions}

Dongwhan Suh made a contribution to the study design, acquisition, interpretation of data, and writing of the manuscript. Woo Lam Jo and Seung Chan Kim made a contribution in carrying out the experiment in vivo and in vitro. Soon Yong Kwon and Yong Sik Kim supervised the investigation and its interpretation. Young Wook Lim took charge of the overall direction and planning and was the principal investigator of the project. All authors made critical feedback and helped shape the study, analysis, and manuscript. The author(s) read and approved the final manuscript.

\section{Funding}

This study was supported by the Advanced Technology Center project (10048394) from the Korea Evaluation Institute of Industrial Technology (KR).

\section{Availability of data and materials}

All data generated or analyzed during this study are included in the published article.

\section{Ethics approval and consent to participate}

The animal experiment procedures were approved by the institutional animal care and use committee of The Catholic University of Korea (CUMC2014-0109-03). The Catholic MASTER Cells supplied by the Catholic Institute of Cell Therapy (CIC, Seoul, Korea) were derived from the human bone marrow donated by healthy donors after informed consent.

\section{Consent for publication}

Not applicable.

\section{Competing interests}

The authors declare that they have no conflict of interests.

\section{Author details}

'Department of Orthopaedic Surgery, College of Medicine, The Catholic University of Korea, Seoul, Republic of Korea. ${ }^{2}$ Department of Orthopaedic Surgery, Daejeon St. Mary's Hospital, College of Medicine, The Catholic University of Korea, Seoul, Republic of Korea. ${ }^{3}$ Department of Orthopaedic Surgery, Seoul St. Mary's Hospital, College of Medicine, The Catholic University of Korea, Seoul, Republic of Korea. ${ }^{4}$ Department of Orthopaedic Surgery, Eunpyeong St. Mary's Hospital, College of Medicine, The Catholic University of Korea, Seoul, Republic of Korea.

Received: 20 June 2020 Accepted: 19 November 2020

Published online: 26 November 2020

References

1. Rivière C, Grappiolo G, Engh CA Jr, Vidalain J-P, Chen A-F, Boehler N, et al. Long-term bone remodelling around 'legendary'cementless femoral stems. EFORT Open Rev. 2018;3(2):45-57.

2. Gasik M, Braem A, Chaudhari A, Duyck J, Vleugels J. Titanium implants with modified surfaces: meta-analysis of in vivo osteointegration. Mater Sci Eng C Mater Biol Appl. 2015;49:152-8.

3. Jinno T, Goldberg VM, Davy D, Stevenson S. Osseointegration of surfaceblasted implants made of titanium alloy and cobalt-chromium alloy in a rabbit intramedullary model. J Biomed Mater Res. 1998;42(1):20-9.

4. Van Noort R. Titanium: the implant material of today. J Mater Sci. 1987; 22(11):3801-11.

5. Jakobsen SS, Baas J, Jakobsen T, Soballe K. Biomechanical implant fixation of CoCrMo coating inferior to titanium coating in a canine implant model. J Biomed Mater Res Part A. 2010;94(1):180-6.

6. Sun Z, lon J. Laser welding of dissimilar metal combinations. J Mater Sci. 1995;30(17):4205-14.

7. Balla VK, Banerjee S, Bose S, Bandyopadhyay A. Direct laser processing of a tantalum coating on titanium for bone replacement structures. Acta biomaterialia. 2010;6(6):2329-34.

8. Berndt CC, Brindley W, Goland A, Herman H, Houck D, Jones K, et al. Current problems in plasma spray processing. J Thermal Spray Technol. 1992;1(4):341.

9. Lundin C. Dissimilar metal welds-transition joints literature review. Welding J. 1982;61(2):58-63.

10. Ryan G, Pandit A, Apatsidis DP. Fabrication methods of porous metals for use in orthopaedic applications. Biomaterials. 2006;27(13):2651-70.

11. Yang Y, Tian J, Tian J, Chen Z, Deng X, Zhang D. Preparation of graded porous titanium coatings on titanium implant materials by plasma spraying. J Biomed Mater Res. 2000;52(2):333-7.

12. Lewis GK, Schlienger E. Practical considerations and capabilities for laser assisted direct metal deposition. Mater Design. 2000;21(4):417-23.

13. Roggensack M, Walter $M$, Böning K. Studies on laser-and plasma-welded titanium. Dent Mater. 1993;9(2):104-7.

14. Santos EC, Shiomi M, Osakada K, Laoui T. Rapid manufacturing of metal components by laser forming. Int J Machine Tools Manufacture. 2006;46(1213):1459-68.

15. Shin T, Park S-J, Kang KS, Kim JS, Kim Y, Lim Y, et al. A laser-aided direct metal tooling technology for artificial joint surface coating. Int J Precision Eng Manuf. 2017;18(2):233-8.

16. Kim SC, Jo WL, Kim YS, Kwon SY, Cho YS, Lim YW. Titanium powder coating using metal 3D printing: a novel coating technology for cobalt-chromium alloy implants. Tissue Eng Regen Med. 2019;16(1):11-8.

17. Harrysson OL, Cansizoglu O, Marcellin-Little DJ, Cormier DR, West HA II. Direct metal fabrication of titanium implants with tailored materials and 
mechanical properties using electron beam melting technology. Mater Sci Eng C. 2008;28(3):366-73.

18. Jaiswal N, Haynesworth SE, Caplan Al, Bruder SP. Osteogenic differentiation of purified, culture-expanded human mesenchymal stem cells in vitro. J Cell Biochem. 1997;64(2):295-312.

19. Ferron M, Wei J, Yoshizawa T, Ducy P, Karsenty G. An ELISA-based method to quantify osteocalcin carboxylation in mice. Biochem Biophys Res Commun. 2010;397(4):691-6.

20. Globus R, Doty S, Lull J, Holmuhamedov E, Humphries M, Damsky C Fibronectin is a survival factor for differentiated osteoblasts. J Cell Sci. 1998; 111(10):1385-93.

21. Al-Nawas B, Groetz K, Goetz H, Duschner H, Wagner W. Comparative histomorphometry and resonance frequency analysis of implants with moderately rough surfaces in a loaded animal model. Clin Oral Implants Res. 2008;19(1):1-8.

22. Shah FA, Omar O, Suska F, Snis A, Matic A, Emanuelsson L, et al. Long-term osseointegration of $3 \mathrm{D}$ printed $\mathrm{CoCr}$ constructs with an interconnected open-pore architecture prepared by electron beam melting. Acta Biomater. 2016:36:296-309.

23. Komori T. Regulation of osteoblast differentiation by transcription factors. $J$ Cell Biochem. 2006;99(5):1233-9.

\section{Publisher's Note}

Springer Nature remains neutral with regard to jurisdictional claims in published maps and institutional affiliations.

Ready to submit your research? Choose BMC and benefit from:

- fast, convenient online submission

- thorough peer review by experienced researchers in your field

- rapid publication on acceptance

- support for research data, including large and complex data types

- gold Open Access which fosters wider collaboration and increased citations

- maximum visibility for your research: over $100 \mathrm{M}$ website views per year

At BMC, research is always in progress.

Learn more biomedcentral.com/submissions 